\title{
THE EFFECT OF THE ANTIOXIDANT DRUG “U-74389G" ON TOTAL PROTEIN LEVELS DURING ISCHEMIA REPERFUSION INJURY IN RATS
}

\author{
Constantinos Tsompos ${ }^{1}$, Constantinos Panoulis ${ }^{2}$, Konstantinos Toutouzas ${ }^{3}$, \\ George Zografos ${ }^{4}$, Apostolos Papalois ${ }^{5}$
}

${ }^{1}$ Department of Obstetrics \& Gynecology, Mesologi County Hospital, Etoloakarnania, Greece

${ }^{2}$ Department of Obstetrics \& Gynecology, Aretaieion Hospital, Athens University, Attiki, Greece

${ }^{3}$ Department of Surgery, Ippokrateion General Hospital, Athens University, Attiki, Greece

${ }^{4}$ Department of Surgery, Ippokrateion General Hospital, Athens University, Attiki, Greece

${ }^{5}$ Experimental Research Center ELPEN Pharmaceuticals, S.A. Inc., Co.

ABSTRACT
The aim of this experimental study was to examine the effect of the antioxidant drug "U-74389G", on rat model and
particularly in an ischemia - reperfusion protocol. The beneficial effect or non-effectiveness of that molecule were
studied biochemically using blood mean total protein levels.
Materials and methods. 40 rats of mean weight $231.875 \mathrm{gr}$ were used in the study. Total protein levels were
measured at 60 min of reperfusion (groups $A$ and $C)$ and at 120 min of reperfusion (groups $B$ and $D), A$ and $B$
without but $C$ and $D$ with $U-74389 G$ administration.
Results were that $U-74389 G$ administration significantly decreased the predicted TP levels by $7.34 \%+1.76 \%$
$(P=0.000)$. Reperfusion time non-significantly increased the predicted TP levels by $1.46 \%+2.12 \%(p=0.410)$.
However, $U-74389 G$ administration and reperfusion time together significantly decreased the TP levels by $4.08 \%+$
$1.10 \%(P=0.000)$.
Conclusions are that $U-74389 G$ administration interacted or not with reperfusion time significantly decreases the
total protein levels.

Keywords: ischemia, U-74389G, total protein, reperfusion

\section{INTRODUCTION}

Ischemia and reperfusion (IR) remain one of the main causes of permanent or transient damage with serious implications on adjacent organs and certainly on patients' health. The use of antioxidant substances has been a research subject for many years. However, even if important progress has been made, satisfactory answers have not been given yet to fundamental questions, such as, how much powerful should an antioxidant be, when should it be administered, and in which dosage. The particularly satisfactory action of the antioxidant $\mathrm{U}-74389 \mathrm{G}$ in tissue protection has been noted in several performed experiments. Since a careful literature search (PubMed - Medline) was conducted, it was realized that this certain antioxidant has been tried in IR experiments. However, just few relative reports were found, not covering completely this particular matter. Also, a lot of publications addressed trials of other similar molecules of aminosteroids (lazaroids) to which the studied molecule also belongs to. U-74389G or better 21-[4(2,6-di-1-pyrrolidinyl-4-pyrimidinyl)-1-piperazinyl] -pregna-1,4,9(11)-triene-3,20-dione maleate salt (1) is an antioxidant which prevents both arachidonic acid-induced and iron-dependent lipid peroxidation. It protects against IR injury in animal 
TABLE 1. The U-74389G influence (+SD) on the levels of some biochemic variables concerning reperfusion (rep) time

\begin{tabular}{|c|c|c|c|c|c|c|c|c|}
\hline Variable & 1h rep & p-value & 1.5h rep & p-value & $2 \mathrm{~h}$ rep & p-value & $\begin{array}{c}\text { interaction of } \\
\text { U-74389G and rep }\end{array}$ & p-value \\
\hline $\begin{array}{l}\text { alkaline } \\
\text { phosphatase }{ }^{66}\end{array}$ & $+22.66 \%+12.37 \%$ & 0.066 & $+31.91 \%+7.69 \%$ & 0.000 & $+41.16 \%+9.65 \%$ & 0.000 & $+17.75 \%+4.79 \%$ & 0.000 \\
\hline sodium $^{67}$ & $+1.22 \%+0.66 \%$ & 0.070 & $+0.17 \%+0.61 \%$ & 0.771 & $-0.87 \%+1.03 \%$ & 0.399 & $-0.32 \%+0.36 \%$ & 0.369 \\
\hline chloride $^{68}$ & $-0.58 \%+0.77 \%$ & 0.453 & $-0.97 \%+0.53 \%$ & 0.087 & $-1.36 \%+0.76 \%$ & 0.111 & $-0.75 \%+0.38 \%$ & 0.015 \\
\hline phosphorus $^{69}$ & $-2.23 \%+5.51 \%$ & 0.796 & $-1.61 \%+3.32 \%$ & 0.578 & $-1 \%+4.48 \%$ & 0.812 & $-1.09 \%+2 \%$ & 0.577 \\
\hline
\end{tabular}

heart, liver and kidney models. These membraneassociating antioxidants (2) are particularly effective in preventing permeability changes in brain microvascular endothelial cells monolayers. The same authors found the influence of U-74389G as depicted at Table 1 on some biochemical variables serum levels in related IR injury experiments $1 \mathrm{~h}$, $1.5 \mathrm{~h}, 2 \mathrm{~h}$ and interaction of $\mathrm{U}-74389 \mathrm{G}$ with reperfusion time after clamp removal in rats.

The aim of this experimental study was to examine the effect of the antioxidant drug "U-74389G" on rat model and particularly in a liver IR protocol. The beneficial effect or non-effectiveness of that molecule were studied by measuring blood mean total protein levels (TP).

\section{MATERIALS AND METHODS}

\section{Animal preparation}

This experimental study was laid out at the Experimental Research Center of ELPEN Pharmaceuticals Co. Inc. S.A. at Pikermi, Attiki and by Veterinary Address of East Attiki Prefecture under 3693/12-11-2010 \& 14/10-1-2012 decisions. All settings needed for the study including of consumables, equipment and substances used, were a courtesy of that S.A. TP levels measurements were performed by Nihon Kohden celltac a MEK-6450 K automatic hematology analyzer with preset rat type and cyanide-free reagents. Albino female Wistar rats were used in accordance with accepted standards of humane animal care. The rats were 16-18 weeks old and became sexually mature at about the sixth week. They were housed in laboratory 7 days before the experiment, having easy access to water and food. The experiment was acute, that is, the animal usage was completed by following experimental set of times without awakening and preservation of the rodents. It is considered (3) that less hypoxemia and less erythropoiesis would occur in the luteal (L) than the follicular (F) phase of the cycle, because the ovarian steroid hormones, progesterone and estrogen, have higher blood levels in $\mathrm{L}$ than in $\mathrm{F}$ phase of the menstrual cycle due to their known effects on ventilation and hemopoiesis. The efficiency of female sex hormone treatment could be related either to the central effects of progesterone and estrogen and/or to the impact of these hormones on erythropoiesis at the kidney/bone marrow level. They were randomly assigned to four experimental groups (10 animals in each group).

1) Ischemia for $45 \mathrm{~min}$ followed by reperfusion for $60 \mathrm{~min}$ (group A).

2) Ischemia for $45 \mathrm{~min}$ followed by reperfusion for $120 \mathrm{~min}$ (group B).

3) Ischemia for $45 \mathrm{~min}$ followed by immediate U-74389G intravenous (IV) administration and reperfusion for $60 \mathrm{~min}$ (group C).

4) Ischemia for $45 \mathrm{~min}$ followed by immediate U-74389G IV administration and reperfusion for 120 min (group D).

Since the rodents were randomly assigned to normally distributed experimental groups, an equal number of animals are expected to be distributed not only at every cycle phase but also uniformly along the sinusoidal fluctuation of every female sex hormone. This distribution equality with neutralizing interactions, disappears the influence of hormonal variability. The molecule U-74389G dose was $10 \mathrm{mg} / \mathrm{Kg}$ body weight of animals.

The experiment started with animals submitted into prenarcosis followed by general anesthesia. Their electrocardiogram and acidometry were continuously monitored. Their inferior aorta flow were excluding by forceps. After exclusion, the protocol of IR was applied, exactly as described in experimental groups. The molecules were administered at the time of reoxygenation, through inferior vena cava after catheterization had been achieved. The TP levels measurement was performed at $60 \mathrm{~min}$ of reperfusion (groups A and C) and at $120 \mathrm{~min}$ of reperfusion (groups B and D).

Serum TP, also known as TP, is a biochemical test for measuring the total amount of protein in serum. Protein in the plasma is made up of globulins, albumin, and fibrinogen. The reference range for TP is typically $60-80 \mathrm{~g} / \mathrm{L}$. It is also sometimes reported as " $6.0-8.0 \mathrm{~g} / \mathrm{dl}$ ", but this may vary depending on the method of analysis. 
The albumins are a family of globular proteins, the most common of which is serum albumin. The albumin family consists of all proteins that are water-soluble, are moderately soluble in concentrated salt solutions, experience heat denaturation and are unique from other blood proteins in that they are not glycosylated. Serum albumin is the most abundant blood plasma protein and is produced in the liver and forms a large proportion of all plasma protein.

The human version is human serum albumin, and it normally constitutes about $50 \%$ of human plasma protein (4). The globulins are a family of globular proteins that have higher molecular weights and water solubility values than the albumins. Some globulins are produced in the liver, while others are made by the immune system. The normal concentration of globulins in human blood is about $2.6-4.6 \mathrm{~g} / \mathrm{dL}$.

The fibrinogen molecule is a soluble, large, and complex glycoprotein, $340 \mathrm{kDa}$ plasma glycoprotein, that is converted by thrombin into fibrin during blood clot formation. Fibrinogen is synthesized in the liver by the hepatocytes (5). The concentration of fibrinogen in the blood plasma is $200-400 \mathrm{mg} / \mathrm{dL}$ (normally measured using the Clauss method).

Rats were submitted into general anesthesia by initial intramuscular (IM) administration of $0.5 \mathrm{cc}$ compound, which constituted of $0.25 \mathrm{cc}$ xylazine, [25 cc, $20 \mathrm{mg} / \mathrm{cc}$ ] and $0.25 \mathrm{cc}$ ketamine hydrochloride $[1000,100 \mathrm{mg} / \mathrm{cc}, 10 \mathrm{cc}]$. Before initiation of laparotomy, $0.03 \mathrm{cc}$ butorphanol $[10 \mathrm{mg} / \mathrm{cc}, 10 \mathrm{cc}]$ anesthetic agent was administered subcutaneously (SC). Continuous oxygen supply was administered during whole experiment performance. Hypoxemia was caused by clamping inferior aorta over renal arteries for $45 \mathrm{~min}$ after laparotomic access was achieved. Reperfusion was induced by removing the clamp and reestablishment of inferior aorta patency. Forty (40) female Wistar albino rats were used of mean weight $231.87 \mathrm{gr}$ [Std. Dev: $36.59 \mathrm{gr}$ ], with min weight $\geq 165$ gr and max weight $\leq 320$ gr. Rats weight could be potentially a confusing factor, e.g. fatter rats to have greater blood TP levels. This suspicion was investigated.

\section{Control groups}

20 control rats of mean weight 252.5 gr [Std. Dev: $39.31 \mathrm{gr}$ ] were subjected to ischemia for 45 min followed by reperfusion.

\section{Group A}

Reperfusion which lasted 60 min concerned 10 controls rats of mean weight 243 gr [Std. Dev:
$45.77 \mathrm{gr}]$ and mean TP levels $5.34 \mathrm{gr} / \mathrm{dl}$ [Std. Dev: $0.60 \mathrm{gr} / \mathrm{dl}]$ (Table 2).

TABLE 2. Weight and total protein levels and Std. Dev. of groups

\begin{tabular}{|l|c|c|c|}
\hline Groups & Variable & Mean & Std. Dev \\
\hline A & Weight & $243 \mathrm{gr}$ & $45.77 \mathrm{gr}$ \\
& TP & $5.34 \mathrm{gr} / \mathrm{dl}$ & $0.60 \mathrm{gr} / \mathrm{dl}$ \\
\hline B & Weight & $262 \mathrm{gr}$ & $31.10 \mathrm{gr}$ \\
& TP & $5.82 \mathrm{gr} / \mathrm{dl}$ & $0.64 \mathrm{gr} / \mathrm{dl}$ \\
\hline C & Weight & $212.5 \mathrm{gr}$ & $17.83 \mathrm{gr}$ \\
& TP & $5 \mathrm{gr} / \mathrm{dl}$ & $0.22 \mathrm{gr} / \mathrm{dl}$ \\
\hline D & Weight & $210 \mathrm{gr}$ & $18.10 \mathrm{gr}$ \\
& TP & $5.03 \mathrm{gr} / \mathrm{dl}$ & $0.27 \mathrm{gr} / \mathrm{dl}$ \\
\hline
\end{tabular}

\section{Group B}

Reperfusion which lasted 120 min concerned 10 controls rats of mean weight 262 gr [Std. Dev: $31.10 \mathrm{gr}$ ] and mean TP levels $5.82 \mathrm{gr} / \mathrm{dl}$ [Std. Dev: $0.64 \mathrm{gr} / \mathrm{dl}]$ (Table 2).

Lazaroid (L) group 20 rats of mean weight 211.25 gr [Std. Dev: $17.53 \mathrm{gr}$ ] suffered by ischemia for $45 \mathrm{~min}$ followed by reperfusion in the beginning of which $10 \mathrm{mg} \mathrm{U}-74389 \mathrm{G} / \mathrm{kg}$ body weight were IV administered.

\section{Group C}

Reperfusion which lasted 60 min concerned 10 L rats of mean weight $212.5 \mathrm{gr}$ [Std. Dev: $17.83 \mathrm{gr}$ ] and mean TP levels $5 \mathrm{gr} / \mathrm{dl}$ [Std. Dev: $0.22 \mathrm{gr} / \mathrm{dl}$ ] (Table 2).

\section{Group D}

Reperfusion which lasted 120 min concerned 10 L rats of mean weight 210 gr [Std. Dev: $18.10 \mathrm{gr}$ ] and mean TP levels $5.03 \mathrm{gr} / \mathrm{dl}$ [Std. Dev: $0.27 \mathrm{gr} / \mathrm{dl}$ ] (Table 2).

TP levels and weight groups of 10 variables were tested for distribution normality by AndersonDarling normality test with 9 degrees of freedom. All distributions were proved normal, skewnesses and kurtosis were excluded and the descriptive statistics for every group were compatible with distribution normality. Parametric tests were substantiated because all prerequisites were satisfied. Every rats weight group initially was compared with each one from 3 remained groups applying statistical paired t-test (Table 3). Any emerging significant difference among TP levels was investigated whether owed in the above mentioned probable significant weight correlation. Every rats TP group initially was compared with other one from 3 remained groups applying statistical paired t-test (Table 3). Applying generalized linear models (glm) with dependant variable the TP levels and independent variables the U-74389G administration or no, the reperfusion time and their interaction, resulted 
in: U-74389G administration significantly decreased the TP levels by $0.56 \mathrm{gr} / \mathrm{dl}[-0.88 \mathrm{gr} / \mathrm{dl}-$ $-0.24 \mathrm{gr} / \mathrm{dl}](\mathrm{P}=0.000)$. This finding was in accordance with paired t-test $(\mathrm{p}=0.0010)$. Reperfusion time non-significantly increased the TP levels by $0.25 \mathrm{gr} / \mathrm{dl}[-0.10 \mathrm{gr} / \mathrm{dl}-0.61 \mathrm{gr} / \mathrm{dl}](\mathrm{P}=0.156)$, also in accordance with the results of paired t-test $(p=0.111)$. However, U-74389G administration and reperfusion time together significantly decreased the TP levels by $0.30 \mathrm{gr} / \mathrm{dl}[-0.50 \mathrm{gr} / \mathrm{dl}--0.10 \mathrm{gr} / \mathrm{dl}]$ $(\mathrm{P}=0.003)$. Reviewing the above and Table 3, Table 4 sums up concerning the alteration influence of U-74389G in connection with reperfusion time.

Inserting the rats weight also as an independent variable at generalized linear models analysis, a very significant relation resulted in $(\mathrm{p}=0.000)$, so as to further investigation was needed. The predicted TP values, adjusted for rats weight were calculated and are depicted at Table 5. Afterwards, the predicted TP values of each one from 4 rats groups were compared with other one from 3 remained groups applying statistical paired t-test. (Table 6).

Applying again the glm with dependant variable the predicted TP values and independent variables the U-74389G administration or no, the reperfusion time and their interaction, resulted in: U-74389G administration significantly decreased the predicted TP levels by $0.38 \mathrm{gr} / \mathrm{dl}[-0.57 \mathrm{gr} / \mathrm{dl}--0.20 \mathrm{gr} / \mathrm{dl}]$ $(\mathrm{P}=0.000)$.

TABLE 3. Statistical significance of mean values difference for groups (DG) after statistical paired t test application

\begin{tabular}{|l|c|c|c|}
\hline DG & Variable & Difference & p-value \\
\hline A-B & Weight & $-19 \mathrm{gr}$ & 0.242 \\
& TP & $-0.48 \mathrm{gr} / \mathrm{dl}$ & 0.109 \\
\hline A-C & Weight & $30.5 \mathrm{gr}$ & 0.067 \\
& TP & $0.34 \mathrm{gr} / \mathrm{dl}$ & 0.096 \\
\hline A-D & Weight & $33 \mathrm{gr}$ & 0.057 \\
& TP & $0.31 \mathrm{gr} / \mathrm{dl}$ & 0.238 \\
\hline B-C & Weight & $49.5 \mathrm{gr}$ & 0.001 \\
& TP & $0.82 \mathrm{gr} / \mathrm{dl}$ & 0.006 \\
\hline B-D & Weight & $52 \mathrm{gr}$ & 0.000 \\
& TP & $0.79 \mathrm{gr} / \mathrm{dl}$ & 0.004 \\
\hline C-D & Weight & $2.5 \mathrm{gr}$ & 0.704 \\
& TP & $-0.03 \mathrm{gr} / \mathrm{dl}$ & 0.807 \\
\hline
\end{tabular}

This finding was in accordance with paired t-test $(\mathrm{P}=0.000)$. Reperfusion time non-significantly increased the predicted TP levels by $0.07 \mathrm{gr} / \mathrm{dl}[-0.14$ $\mathrm{gr} / \mathrm{dl}-0.30 \mathrm{gr} / \mathrm{dl}](\mathrm{P}=0.483)$ also in accordance with the results of paired t-test $(\mathrm{P}=0.337)$.

However, U-74389G administration and reperfusion time together significantly decreased the TP levels by $0.21 \mathrm{gr} / \mathrm{dl}[-0.33 \mathrm{gr} / \mathrm{dl}--0.10 \mathrm{gr} / \mathrm{dl}]$ $(\mathrm{P}=0.000)$.

TABLE 5. Mean predicted total protein values adjusted for weight and Std. Dev. of groups

\begin{tabular}{|l|c|c|}
\hline Groups & Mean & Std. Dev \\
\hline A & $5.40 \mathrm{gr} / \mathrm{dl}$ & $0.43 \mathrm{gr} / \mathrm{dl}$ \\
\hline B & $5.58 \mathrm{gr} / \mathrm{dl}$ & $0.29 \mathrm{gr} / \mathrm{dl}$ \\
\hline C & $5.11 \mathrm{gr} / \mathrm{dl}$ & $0.16 \mathrm{gr} / \mathrm{dl}$ \\
\hline D & $5.09 \mathrm{gr} / \mathrm{dl}$ & $0.17 \mathrm{gr} / \mathrm{dl}$ \\
\hline
\end{tabular}

TABLE 6. Statistical significance of mean values difference for groups (DG) after statistical paired t test application

\begin{tabular}{|l|c|c|}
\hline DG & Difference & p-value \\
\hline A-B & $-0.17 \mathrm{gr} / \mathrm{dl}$ & 0.242 \\
\hline A-C & $0.28 \mathrm{gr} / \mathrm{dl}$ & 0.067 \\
\hline A-D & $0.31 \mathrm{gr} / \mathrm{dl}$ & 0.057 \\
\hline$B-C$ & $0.46 \mathrm{gr} / \mathrm{dl}$ & 0.001 \\
\hline B-D & $0.49 \mathrm{gr} / \mathrm{dl}$ & 0.000 \\
\hline C-D & $0.02 \mathrm{gr} / \mathrm{dl}$ & 0.704 \\
\hline
\end{tabular}

TABLE 7. The decreasing influence of U-74389G in connection with reperfusion time

\begin{tabular}{|l|l|c|l|l|}
\hline Decrease & $95 \% \mathrm{c}$. in. & Reperfusion & \multicolumn{2}{l|}{$\mathrm{p}$-values } \\
\cline { 4 - 5 } & & time & t-test & $\mathrm{glm}$ \\
\hline$-0.28 \mathrm{gr} / \mathrm{dl}$ & $-0.59 \mathrm{gr} / \mathrm{dl}-0.02 \mathrm{gr} / \mathrm{dl}$ & $1 \mathrm{~h}$ & 0.067 & 0.065 \\
\hline$-0.38 \mathrm{gr} / \mathrm{dl}$ & $-0.57 \mathrm{gr} / \mathrm{dl}--0.20 \mathrm{gr} / \mathrm{dl}$ & $1.5 \mathrm{~h}$ & 0.000 & 0.000 \\
\hline$-0.49 \mathrm{gr} / \mathrm{dl}$ & $-0.71 \mathrm{gr} / \mathrm{dl}--0.26 \mathrm{gr} / \mathrm{dl}$ & $2 \mathrm{~h}$ & 0.000 & 0.000 \\
\hline$+0.07 \mathrm{gr} / \mathrm{dl}$ & $-0.14 \mathrm{gr} / \mathrm{dl}-0.30 \mathrm{gr} / \mathrm{dl}$ & $\begin{array}{c}\text { reperfusion } \\
\text { time }\end{array}$ & 0.483 & 0.33 \\
& & & & 0.000 \\
\hline$-0.21 \mathrm{gr} / \mathrm{dl}$ & $-0.33 \mathrm{gr} / \mathrm{dl}--0.10 \mathrm{gr} / \mathrm{dl}$ & interaction & & \multicolumn{3}{|l}{} \\
\hline
\end{tabular}

TABLE 8. The (\%) decreasing influence of U-74389G in connection with reperfusion time

\begin{tabular}{|l|c|c|c|}
\hline Decrease & \pm SD & Reperfusion time & p-values \\
\hline$-5.48 \%$ & $\pm 2.99 \%$ & $1 \mathrm{~h}$ & 0.066 \\
\hline$-7.34 \%$ & $\pm 1.76 \%$ & $1.5 \mathrm{~h}$ & 0.000 \\
\hline$-9.20 \%$ & $\pm 2.16 \%$ & $2 \mathrm{~h}$ & 0.000 \\
\hline$+1.46 \%$ & $\pm 2.12 \%$ & reperfusion time & 0.410 \\
\hline$-4.08 \%$ & $\pm 1.10 \%$ & interaction & 0.000 \\
\hline
\end{tabular}

TABLE 4. The decreasing influence of $U-74389 \mathrm{G}$ in connection with reperfusion time

\begin{tabular}{|l|c|c|c|c|}
\hline \multirow{2}{*}{ Decrease } & 95\% c. in. & Reperfusion time & \multicolumn{2}{|c|}{ p-values } \\
\cline { 3 - 5 } & & & t-test & glm \\
\hline$-0.34 \mathrm{gr} / \mathrm{dl}$ & $-0.76 \mathrm{gr} / \mathrm{dl}-0.08 \mathrm{gr} / \mathrm{dl}$ & $1 \mathrm{~h}$ & 0.096 & 0.112 \\
\hline$-0.56 \mathrm{gr} / \mathrm{dl}$ & $-0.88 \mathrm{gr} / \mathrm{dl}--0.24 \mathrm{gr} / \mathrm{dl}$ & $1.5 \mathrm{~h}$ & 0.001 & 0.000 \\
\hline$-0.79 \mathrm{gr} / \mathrm{dl}$ & $-1.25 \mathrm{gr} / \mathrm{dl}--0.32 \mathrm{gr} / \mathrm{dl}$ & $2 \mathrm{~h}$ & 0.004 & 0.002 \\
\hline$+0.25 \mathrm{gr} / \mathrm{dl}$ & $-0.10 \mathrm{gr} / \mathrm{dl}-0.61 \mathrm{gr} / \mathrm{dl}$ & reperfusion time & 0.156 & 0.111 \\
\hline$-0.30 \mathrm{gr} / \mathrm{dl}$ & $-0.50 \mathrm{gr} / \mathrm{dl}--0.10 \mathrm{gr} / \mathrm{dl}$ & interaction & & 0.003 \\
\hline
\end{tabular}


TP concentrations below the reference range and proportionally expected low albumin (hypoalbuminemia) usually reflect low albumin concentration, for instance in liver disease or acute infection. High TP levels and proportionally expected high albumin levels (hyperalbuminemia) are almost always caused by dehydration. Other situations are individualized. Rarely, low TP levels may be a sign of immunodeficiency. Concentrations above the reference range are found in paraproteinaemia, Hodgkin's lymphoma, leukaemia or any condition causing an increase in immunoglobulins. Low albumin (hypoalbuminemia) may be caused by liver disease, nephrotic syndrome, burns, protein-losing enteropathy, malabsorption, malnutrition, late pregnancy, artefact, genetic variations and malignancy. Farrugia A reports (6) that in some cases of retinol (Vitamin A) deficiency, the albumin level can be elevated to high-normal values (e.g., $4.9 \mathrm{~g} / \mathrm{dL}$ ) since all-trans retinoic acid lack, up regulate human albumin production. Marucco et al described (7) congenital fibrinogen deficiency (afibrinogenemia) or disturbed function of fibrinogen in a few cases. Acharya SS et al claims that it can lead (8) to either bleeding or thromboembolic complications, or is clinically without pathological findings.

Lang $\mathrm{T}$ et al found (9) more common acquired deficiency stages after hemodilution, blood losses and/or consumption such as in trauma patients, during some phases of disseminated intravascular coagulation (DIC), and also in sepsis.

\section{DISCUSSION}

Conclusions were tried to be drawn for the effects of U-74389G on an isolated organ like the brain, although, any usual anti-inflammatory drug could have some of these effects, and many more on different metabolic areas (as in fact published for different seric ions), which would justify seperated studies, in this complex system. Koriem KM et al restored (10) serum TP, albumin, globulin, albumin/globulin ratio, brain serotonin, norepinephrine and dopamine, blood and liver superoxide dismutase, and glutathione peroxidase levels to normal values by administration of $60 \mathrm{mg} / \mathrm{kg}$ chlorogenic acid and $40 \mathrm{mg} / \mathrm{kg}$ caftaric acid prior to $10 \mathrm{mg} / \mathrm{kg}$ methamphetamine injections twice a day over a week preventing liver toxicity and oxidative stress in male albino rats. Rondi S. et al showed (11) the neuroprotective activity, significantly $(\mathrm{P}<0.05)$ increasing the latency in the hotplate model associated with significant $(P<0.05)$ increase in serum
TP levels, treating by daily doses of - an antioxidant defense and lipid-lowering HMG-CoA inhibitor - rosuvastatin $(10 \mathrm{mg} / \mathrm{kg})$, or metformin (120 $\mathrm{mg} / \mathrm{kg}$ ), or glimepiride $(1 \mathrm{mg} / \mathrm{kg})$, or their combination for a period of 6 weeks in induced type 2 diabetic Wistar rats. Mustafa H.N. et al showed (12) elevation on serum TP associated with protective effect of vitamin C $(100 \mathrm{mg} / \mathrm{kg})$ or vitamin $\mathrm{E}$ $(200 \mathrm{mg} / \mathrm{kg}$ ) daily for 3 days and their combination, although vitamin $\mathrm{E}$ is more efficient against oxidative stress and hepatic and brain damage, and histological architecture of the liver in Wistar rats' model of acute hepatic encephalopathy elicited by thioacetamide TAA $(300 \mathrm{mg} / \mathrm{kg})$ once intraperitoneally (IP). Eigbibhalu U.G. et al found (13) the brain serotonin levels significantly higher except serum TP after administration of $1.25 / 25 \mathrm{mg}$ base/ $\mathrm{kg}$ body weight of sulfadoxine - pyrimethamine (SP), $3.3 \mathrm{mg} / \mathrm{kg}$ body weight of artesunate (A) and SPA for 4 weeks compared with the control ones throughout the duration of the study in rabbits. Daimon M. et al showed (14) a significantly increased risk for total mortality in subjects with higher PRA (log-rank $\mathrm{P}<.001)$ after adjustment for serum TP; hazard ratio: 2.12; [1.47-3.06]. Higher PRA $(\geq 2.0 \mathrm{ng} /[\mathrm{mL} \mathrm{h}])$ was a significant and independent risk factor for increased total mortality $(2.63,1.57-4.41)$ in this Japanese population and may be a marker for subjects at an increased risk of total mortality. Zhang H. et al showed (15) that hypoproteinemia and undernutrition were serious with premorbid nutritional index sequenced by sensitivity being: serum prealbumin $>$ serum albumin $>$ serum TP; measured within 24 hours after stroke onset and every week routinely, but higher prevalence of dysphagia, post-stroke pneumonia, and gastrointestinal hemorrhage in dying patients with acute ischemic stroke from admission to death, especially in patients with recurrent ischemic stroke, compared to their normal range and first-ever stroke group ( $\mathrm{P}<0.01)$. Okokon JE et al caused (16) dosedependent non-significant increases in bleeding time, clotting time, albumin levels and histopathologic lesions in brain but significant $(\mathrm{P}<0.05-0.01)$ increases in the level of serum TP, administering a traditional malarial remedy - extract of Croton zambesicus $(27-81 \mathrm{mg} / \mathrm{kg})$ in subchronic treated rats for 21 days than control ones. Obochi GO et al showed (17) that 30 days interaction of melatonin $100 \mathrm{mg} / \mathrm{kg}$ with caffeine $100 \mathrm{mg} / \mathrm{kg}$ enhanced protein synthesis; stimulated gonadotrophin release, could be used as oral contraceptive for women, may be beneficial in the treatment of impotence (androgen depression); stimulated tryptophan me- 
tabolism, which prevents vitamin B6 deficiency, negative nitrogen balance, tissue wasting and accumulation of xanthurenic acid, which promotes sleep; and could be beneficial in the treatment of hyper cholesterolemia and post menopausal osteoporosis than control hosts ones. Asano K et al found (18), low preoperative Karnofsky Performance Score (KPS), high intraoperative blood loss, and a large difference between pre- and postoperative $\mathrm{Hb}$ levels as significant risk factors for postoperative systemic complications. $(\mathrm{p}=0.0450)$ estimated at $41.7 \%$ in elderly patients 70 years of age or older, who underwent surgical brain tumor removal. Sukumaran K et al suggested (19) that 120 days dietary phosphorus (dP) deficiency caused organ specific induction of 70 kilodalton heat shock proteins (HSP70) expression observed only in low dP, in brain but not in liver and muscle tissues of catla fingerlings fish. Serum albumin and $\mathrm{A} / \mathrm{G}$ ratio was found to follow the increasing $\mathrm{dP}$ grading $(\mathrm{P}<0.05)$ at the end of feeding trial, while serum globulin and TP levels remained unaffected. Mohebbi-Fani M et al found (20) serum TP and urea nitrogen levels measured every 10 days higher but no gross or microscopic lesion detected in feedlot lambs' brains attributed to the toxic effects of 5,10 , or $15 \mathrm{~g}$ methenamine than those in control group, concluding that it can be used as a non-protein nitrogenous compound daily in their feed for 100 days without serious side-effects on health status compared with control diet low in crude protein without methenamine. Foley JE et al assessed (21) the positive anticoronavirus IgG titer in cerebrospinal fluid, high serum TP concentration, periventricular contrast enhancement, ventricular dilatation, hydrocephalus patchy and focal lesions as the most useful antemortem indicators of primary neurologic disease in most cats with neurologic and ocular forms of $\mathrm{Fe}-$ line infectious peritonitis (FIP) than control with nonneurologic ones. Mohamed OS et al characterized (22) cotoran poisoning [25 to $4000 \mathrm{mg}$ cotoran $/ \mathrm{kg}$ by drench] by grinding of teeth, ruminal tympany, mydriasis, dyspnea, staggering, paresis of the hind and forelimbs, recumbency, widespread congestion and hemorrhage accompanied by significant decreases in serum TP levels in 6-9-mo-old clinically healthy desert sheep. Stewart DJ et al most closely negatively associated (23) cardiac doxorubicin concentrations with factors as time from last treatment divided by serum TP and albumin levels, while factors most closely positively associated with cardiac doxorubicinol concentrations were cumulative doxorubicin dose and TP levels. Doxorubicin may be gradually converted to doxo- rubicinol in human tissues where may play a role in local toxicity. Takagi $\mathrm{K}$ et al characterized (24) Kawasaki disease (KD) meningoencephalitis in acute stage, as a syndrome with disturbance of consciousness and seizures developed as status convulsions, $50 \%$ electroencephalograms (EEG) abnormalities, fluid collection in frontal extracerebral space, monocyte-predominant pleocytosis in cerebrospinal fluid (CSF), serum TP levels $(\mathrm{P}<0.01)$, and serum albumin levels $(\mathrm{P}<0.01)$ also significantly lower due to vasculitis of small arteries, arterioles, capillaries, and venules, which consists of infiltration of lymphocytes and large mononuclear cells and edema, with unique neurological sequela the hearing difficulty in $20 \%$ of patients 3 years after the onset and general favorable_prognosis. Hoffman A et al associated (25) decreased serum TP concentration with cyclosporine $(50 \mathrm{mg} / \mathrm{kg} \mathrm{im})$ treatment for 3 days, while cyclosporine-pretreated rats significantly slept (loss of righting reflex) for $71.11 \%$ more time and evaluated significantly lower heptabarbital concentrations in serum, brain, and CSF after heptabarbital $(45 \mathrm{mg} / \mathrm{kg}$ iv) injection on the third day in adult female Wistar rats than control ones. Wanwimolruk S et al decreased (26) the starvation-associated sensitivity of the central nervous system to the hypnotic effect of slowly IV infused phenobarbital to righting reflex loss onset due to higher phenobarbital concentrations in serum, brain and cerebrospinal fluid and reversed it slightly by refeeding for 2 days and persisted even after 7 days of refeeding but without the decreased body weight and serum TP concentration normalization in adult male Sprague-Dawley rats than control (fed) ones. Auer L et al showed (27) important rises in serum $\alpha-2$ by three to four times over normal values, $\alpha-2 M$ globulins and $\alpha-1$ globulin by less marked increase, directly correlated with the amount of craniocerebral trauma lesions, while $\gamma$ globulin, on average, was diminished in the first week and $\alpha-2 \mathrm{M}$ changes were rather irregular with a tendency to severe decrease during the first days in patients with a bad prognosis. C.E. Shaw reports that neurones are not replaced (28) and so must continue to function for many years. Their metabolic activity generates free radicals capable of causing oxidative damage to protein, lipid and nucleic acids, which need to be repaired or replaced. This continuous oxidative stress is likely to be most severe in cells with a high metabolic demand, such as motor neurons. Signs of free radical injury can be found at post mortem in degenerating motor neurons in motor neurone disease (MND) and mutant SOD1 transgenic mice, but the evidence is still circumstantial and does not 
prove that oxidative injury has a primary role in causing MND.

A lot of clinical situations prove the association between TP levels with ischemia. Peng $\mathrm{W}$ et al increased (29) the resistance to surgical stress by dietary preconditioning lacking essential nutrients in a mouse IR model injury. 6 to 14 days TP deprivation protected against renal and hepatic IR injury, resulting in preserved organ function. The amino acid starvation response and translational control is implicated in stress protection. Thus, short-term dietary interventions that modulate amino acid sensing can confer stress resistance in related IR models of surgical injury. Nayak AR et al suggested (30) TP levels as a predictor for severity of acute ischemic stroke (AIS) attacks. Significant TP levels changes were observed at all endpoints from admission until follow-up expiration in AIS patients than matched healthy control ones. van der Hoeven JA et al studied (31) the progressive organ and also kidney dysfunction by monitoring serum TP content. Dysfunction was not only most pronounced in hemodynamically unstable brain-dead donors, but also when hemodynamic instability in brain-dead donors was not corrected, kidney dysfunction was enhanced predisposing the graft for additional IR injury in Wistar rats. Loehe F et al found (32) the percentage of TP content, significantly elevated in the bronchoalveolar lavage (BAL) fluid of nonheart-beating donors (NHBD) group than HBD one, after $24 \mathrm{~h}$ total IR period in allotransplanted left lungs native-bred pigs. Sokolowski A et al provoked (33) already a decreased serum TP content in first 4-8 h of experimental acute pancreatitis in rats. Simmons RD et al indicated (34) that the more caudal significant vasogenic edema increases, the greater differential focal subsequent TP levels increase, during experimental autoimmune encephalomyelitis (EAE) in rat spinal cord. Mrsulja BB et al found (35) reduced TP levels after bilateral totally reversible common carotid arteries IR in gerbils. Also, TP levels are perhaps influenced by U-74389G. Shopova VL et al non-significantly increased (36) the TP content by the combined treatment with paraquat dichloride orally at $80 \mathrm{mg} / \mathrm{kg}$ and U-74389G (IP twice $2 \mathrm{~h}$ before paraquat with $10 \mathrm{mg} / \mathrm{kg}$ and four hours later $5 \mathrm{mg} / \mathrm{kg}$ ) less than paraquat application alone in BAL fluid of male Wistar rats. It is concluded that the lazaroid U$74389 \mathrm{G}$ reduces the pneumotoxic effects of paraquat due to antilipidperoxidation activity and membrane-stabilizing effect until day 3 after the treatment. Moore RM et al monitored (37) nonsignificant differences on plasma TP concentrations in horses groups across time, after 21-aminosteroid U-74389G administration [10 $\mathrm{mg} / \mathrm{kg}$ solution] via the jugular vein 30 minutes prior to large colonic arterial 6 hours IR.

From comparative studies, Vignes JR et al suggested (38) decreased neuronal death to $30.25 \%$ forU-74500A, $34.5 \%$ for U-74389G and $37.5 \%$ for $\mathrm{U}-83836 \mathrm{E}$ treatments added to neuron cultures at concentrations of $10^{-7-5} \mathrm{M}$ simultaneously with cyanide during 6h. Acka G et al concluded (39) that U-74389G is more beneficial 10 min after permanent occlusion, than both hyperbaric oxygen (HBO) which significantly reduced by $38.67 \%(\mathrm{p}<0.05)$ the infarct volumes and combined therapy $\mathrm{HBO}+$ U74389G $3 \mathrm{mg} / \mathrm{kg}(\mathrm{p}<0.05)$ which failed to significantly improve infarct volumes more than $32.32 \%$ of either single treatment after 3 days, in male Wistar rats. Horáková L et al assessed (40) the preventive effect concerning lipid peroxidation decreased in the order: buthylated hydroxytoluene (BHT) (3.5), stobadine (ST) (35), serotonin (54), trolox (98), U 74389G (160), melatonin (3100), methylprednisolone (without effect) the numbers in the brackets represent IC50 in $\mu \mathrm{mol} / 1$ and spin traps interfered with thiobarbituric acid reactive substances (TBARS) determination as a marker of lipid peroxidation. The preventive effect of antioxidants $(30 \mu \mathrm{mol} / \mathrm{l})$ concerning creatine kinase (CK) activity as a selected marker of oxidative modification of proteins, was decreased in the order: BHT (30), trolox (75), stobadine (ST) (77), $\alpha$-phenyl-Ntert-buthylnitrone (PBN) (87), sodium salt of N-tert-buthyl-C-(phenyl-2-sulfone) nitrone (SPBN) (90), nonglucocorticoid steroid U 74389G, methylprednisolone and serotonin (without preventive effects) the numbers in the brackets represent the loss of CK activity in percentages, when $100 \%$ was the loss of CK activity in the absence of any antioxidant. Corasaniti MT et al prevented apoptosis or protection (41) by NS398 (10 mg/kg IP), a selective inhibitor of cyclooxygenase type 2 (COX-2) activity, by NMDA receptor antagonists, such as MK801 (0.3 mg/kg IP) and CGP040116 (10 mg/kg IP) and by the free radical scavenger, U-74389G $(10 \mathrm{mg} / \mathrm{kg} \mathrm{IP})$, supporting a glutamate-mediated, excitotoxic mechanism of apoptotic death in individual rats neocortical cells. Vlkolinský $\mathrm{R}$ et al suggested (42) the following rank order of potency, comparing the protective effect of compounds tested on population spikes recovery: U-74389G $>$ pyridoindole stobadine $>$ melatonin $>>$ trolox, antioxidants with remarkably different chemical structures, exerting neuroprotective activity, probably determined by antioxidative properties of these 
compounds. Durmaz R et al found (43) U-83836E having an $50 \%$ inhibitory concentrations (IC50) of $37.5 \mathrm{mM}$ and $\mathrm{U}-74389 \mathrm{G}$ to be more cytotoxic in primary culture than 5th subculture cell lines. U-83836E had IC50 of $6.525 \mathrm{mM}$ in the glioblastoma multiforme primary cultures at doses ranging between $10^{-1-(+2)} \mathrm{mM}$. The IC50 value of U-74389G was calculated as $91 \mathrm{mM}$ in only one patients. While the IC50 of U-83836E was $45 \mathrm{mM}$, U-74389G showed no cytotoxic effect, on C6 glioma cells. Kondziolka D et al noted (44) significant improvements by $34.78 \%(\mathrm{p}=0.02)$ in median survival and decreased mean diameter by $40.74 \%$ $(\mathrm{p}=0.002)$ after radiosurgery (RS) alone, and by $156.52 \%(\mathrm{p}<0.0001)$ and $46.29 \%(\mathrm{p}=0.0002)$ respectively after RS plus 21-aminosteroid than control group, after $10^{6} \mathrm{C} 6$ glioma cells tumor implantation. The tumor grew as a hypercellular, compact mass in control group. Evidence of RS group peritumoral edema was 2.8 -fold $(\mathrm{p}=0.006)$ and of vasculopathy 5.4-fold more frequent $(\mathrm{p}=0.005)$ compared with control group and aminosteroid-treated rats respectively. Schmid-Elsaesser $\mathrm{R}$ et al concluded (45) that U-101033E improved neurological function from postoperative day 4 to 7 and reduced total infarct volume by $112 \%$, U-74389G did not improve neurological recovery, but both drugs in a dosage of $3 \times 3 \mathrm{mg} / \mathrm{kg}$ IV around ischemia, showed generally significantly less postoperative deficits and reduced total infarct volume by $116 \%(\mathrm{P}<0.05)$. Cortical infarct volume was significantly reduced in all treatment groups after 7 days but only U$101033 \mathrm{E}$ and combination therapy protected the basal ganglia from infarction in Sprague-Dawley rats. Kondziolka D et al reduced (46) radiation-induced vasculopathy and prevented regional edema administering high-dose aminosteroid $(\geq 15 \mathrm{mg} / \mathrm{kg}$ ) at 90 days $(\mathrm{P}=0.06)$ and at 150 days $(\mathrm{P}=0.03)$ 1 hour before radiosurgery at $100-G y$ radiation in normal rat frontal lobe. Low-dose aminosteroid $(5 \mathrm{mg} / \mathrm{kg})$ and corticosteroid methylprednisolone $(2 \mathrm{mg} / \mathrm{kg})$ provided no protection. Marion DW et al concluded (47) that combination therapy with hypothermia (32 degrees $\mathrm{C}$ for $4 \mathrm{~h}$ ) and 21 -aminosteroids (U-74389G, Upjohn, $10 \mathrm{mg} / \mathrm{kg}$ IV, repeated $3 \mathrm{~h}$ after the first dose) although caused significant reductions in the number of stained axons (48\%), was no more efficacious than either therapy alone, and that 21 -aminosteroid therapy was less efficacious (35\%) than hypothermia $(55 \%)$ at 10 or $25 \mathrm{~min}(\mathrm{p}=0.01)$ after injury, but more efficacious at $40 \mathrm{~min}$ in a rodent model. Stanimirovic DB et al abolished (48) the oxidant-evoked decrease in Na,K-ATPase activity in cerebromicrovascular endothelial cells
(RCEC) membrane 'permeability' resulted primarily from changes in membrane lipids, and implicate the inhibition of $\mathrm{Na}, \mathrm{K}-\mathrm{ATP}$ ase in a mechanism responsible for increased membrane lipid peroxidation (TBARM) in presence of the steroid antioxidants U-74500A and U-74389G $(5-20 \mu \mathrm{M})$ for exposure times over 4 hours. Smith D et al suggested (49) anti-inflammatory therapy in clinical management of Niemann-Pick disease type $\mathrm{C} 1$ (NPC1) - a neurodegenerative lysosomal disorder characterized by neuro-inflammation - combined or not with substrate reduction therapy (SRT), since NSAIDs significantly prolonged the lifespan and slowed the onset of clinical signs, while anti-oxidant therapy was of no significant benefit. Combining NSAID therapy with SRT resulted in additive benefit in NPC1 mice. Tripathy D et al documented (50) the beneficial effects of anti-inflammatory drugs in neurodegenerative diseases, such as Alzheimer's disease (AD) characterized by oxidant and inflammatory stress. Pretreatment of cerebral cortical neuronal cultures with acetaminophen $(50 \mu \mathrm{M})$ which has anti-oxidant and anti-inflammatory effects on neurons suggests also a heretofore unappreciated therapeutic potential because increases neuronal cell survival, inhibits the expression of cytokines and chemokines, increases expression of the anti-apoptotic protein $\mathrm{Bcl} 2$ in brain neurons, decreases the menadione-induced elevation of the proapoptotic protein and superoxide levels and cleaves caspase 3. Bates KA et al showed (51) that administration of ibuprofen results in a reduction of oxidative stress also in Alzheimer's disease which is characterised by abnormal extracellular deposition of a $4 \mathrm{kDa}$ peptide termed $\beta$-amyloid, neuronal loss, oxidative stress and chronic astrocytosis and microgliosis exhibiting prolonged oxidative stress with lipid peroxidation and protein carbonyl formation.

Concerning the action of U-74389G in brain, Bimpis A et al considered (52) the administration of $\mathrm{U}-74389 \mathrm{G}$ as neuroprotective provided that $\mathrm{Na}(+), \mathrm{K}(+)-$ and $\mathrm{Mg}(2+)$-ATPase inhibition might diminish the local ATP consumption, since their levels and activity neither decrease nor change, so as being responsible for a very large part of neuronal energy expenditure in the perihematomal basal ganglia territory in a spontaneous porcine intracerebral hemorrhage $(\mathrm{ICH})$ model. Bimpis A et al demonstrated (53) the U-74389G administration as neuroprotectant after the enhancement of cholinergic response throught the activation of acetylcholinesterase (AchE); which counteracts the inflammatory responses following 4 and $24 \mathrm{~h}$ the induced 
porcine ICH model. Durmaz R et al suggested (54) the U-74389G for the acute treatment of cerebral ischemia since its administration at two times as $5 \mathrm{mg} / \mathrm{kg}$ lowered the post-ischemic reperfusion injury cerebral edema and neuronal necrosis, protected blood-brain barrier, significantly restored the extravasation of Evan's blue dye into brain $(p<0.001)$, significantly attenuated neuronal necrosis $(p<0.001)$ which was determined in the hippocampal CA1 subfield, enhanced the $\mathrm{Mg}(2+) / \mathrm{Ca}(2+)$-ATPase activity $(\mathrm{p}<0.01)$ and fully recovered the $\mathrm{Na}(+) / \mathrm{K}(+)-$ ATPase activity $(\mathrm{p}>0.05)$ concomitant with the stabilizing of membrane-bound enzymes compared to vehicle-treated group of rats. Clement $\mathrm{HW}$ et al attenuated (55) the significant reduction of 3,4-dihydroxyphenylacetic acid (DOPAC) activity in the ipsilateral striatum than contralateral side one, accordant with the view that radical mechanisms impair the rat nigrostriatal system induced by oligemia, by pretreatment with U-74389G, injected 20 min before operation. Zhang $\mathrm{F}$ et al proved (56) the antioxidant and antiapoptotic properties of U-74389G from the reduced concentrations of MDA, partially restored activities of SOD and concentrations of GSH and the significantly reduced number of apoptotic cells $(\mathrm{P}<0.05)$ compared with the control group, particularily before the establishment of ischemia than before reperfusion in rats ischemic brains. Kim GW et al concluded (57) that U-74389G (10 mg/kg, 30 minutes around IR) attenuated caspase-3 immunoreactivity up-regulation which is related with apoptotic cell death and subsequent cortical infarction, while DNA fragmentation, laddering and the final lesion was detected smaller in the antioxidant-treated group, 6 and 24 hours after photothrombotic IR compared with the untreated group. Heim C et al impaired (58) the animals' learning ability when lazaroid U-74389G, a potent inhibitor of iron-induced lipid peroxidation, was applied one week after the oligemic episode, but totally prevented the late learning impairments in combined intrastriatal $0.3 \mu \mathrm{g}$ U-74389G and $0.06 \mu \mathrm{g}$ ferric chloride $(\mathrm{FeCl} 3)$ in median adult and aged animals and possibly received reliable neuroprotective properties after clinical studies of lazaroids in humans. Hülsmann $\mathrm{S}$ et al found (59) $30.15 \%$ less appearance of anoxic terminal negativity (ATN)-latency spikes recorded in the CA1 region, with application of $\mathrm{U}-74389 \mathrm{G}$ than control ones, concluding that its cerebroprotective effect is not mediated via direct membrane stabilization during hypoxia in guinea pig hippocampal slices. Fabian RH et al significantly reduced (60) extracellular superoxide anion concentrations dissociated from non significantly reduced local cerebral perfusion (CBFld) 60 min after U-74389G in a dose of 3 $\mathrm{mg} / \mathrm{kg}$ after traumatic brain injury (TBI). Bagetta $\mathrm{G}$ et al delayed (61) the onset of motor and electrocortical (ECoG) discharge seizures, reduced the number of epileptogenic discharges and prevented the hippocampus damage mediated by free oxygen radicals typically observed in rats receiving an injection of dendrotoxin $\mathrm{K}$ (DTx-K) 35 pmol alone which causes a significant loss of CA3 pyramidal neurons ipsilaterally, after systemic IP administration of U-74389G $(5 \mathrm{mg} / \mathrm{kg}$ given $30 \mathrm{~min}$ beforehand), but not of $\alpha$-DTx, (35 pmol), a DTx-K homologue, which preferentially inhibits a slowly inactivating, voltage-dependent $\mathrm{K}+$ conductance in nerve cells. Lee SH et al revealed (62) that $\mathrm{U}-74389 \mathrm{G}(5 \mathrm{mg} / \mathrm{kg}$ IP injected $\mathrm{x} 3$ ) attenuated delayed pyramidal neuronal death increasing the number of living neurons by $137.76 \%, 146.80 \%$, $114.36 \%$ but decreasing by $45.74 \%$ than control group $(\mathrm{P}<0.05)$ one week after hippocampal CA1 subfield of global cerebral ischemia when it was administered 30 minutes before occlusion, at the time, 30 minutes and 60 minutes of reperfusion in adult male Wistar rats ischemic episode respectively. Zhang $J$ et al greatly attenuated (63) the three times increased 2,3-DHBA levels than baseline value and the excitatory amino acid-mediating the highly reactive hydroxyl radical $\mathrm{OH}$. production at $60 \mathrm{~min}$ of reperfusion after U-74389G administration $30 \mathrm{~min}$ before ischemia in rat hippocampus. Farbiszewski R et al suggested (64) the protective effect of U-74389G restoring the activities of superoxide dismutase, glutathione reductase, total and free sulfhydryl groups and thiobarbituric acidreactive substances levels to normal values in rats IR induced brain injury. Van Dyke $\mathrm{K}$ et al considered macrophages able to produce (65) the anion of an oxidizing acid known as peroxynitrite (OONO). This material is formed from two free radical gases, namely superoxide anion [.O2]- and nitric oxide $(. \mathrm{N}=\mathrm{O})$. Therefore, when it oxidizes a substance (such as protein) peroxynitrite disappears. The brain contains cells called microglia which are produced from monocytes - this is - differentiated macrophages which produce large amounts of peroxynitrite when activated by particles (silica) or infectious agents (lipopolysaccharide or interferon). Microglia produce highly oxidizing substances but production of peroxynitrite from these cells has never been measured. Assuming that microglia produce peroxynitrite, or other similar oxidants, anti-oxidant and anti-inflammatory drugs along with large doses of anti-oxidant vitamin $\mathrm{C}$ and $\mathrm{E}$ 
should be potentially helpful in treatment of early forms of Alzheimer's disease.

\section{CONCLUSION}

U-74389G administration interacted or not with reperfusion time significantly decreases the TP levels. This information as well the protective effect of U-74389G on CNS, must be into consideration upon laboratory investigation of various neurologic, immunologic and nutritional situations. Further clinical trials must be held in animal or human populations.

\section{REFERENCES}

1. https://www.caymanchem.com/app/template/Product.vm/catalog/ 75860.

2. Fenglin Shi, Jennifer Cavitt, Kenneth L. Audus. 21-aminosteroid and 2-(aminomethyl)chromans inhibition of arachidonic acid-induced lipid peroxidation and permeability enhancement in bovine brain microvessel endothelial cell monolayers. Free Radical Biology and Medicine, 19(3), 349-357 (1995).

3. Giannattasio C., Failla M., Grappiolo A., Stella M.L., Del Bo A., Colombo M., Mancia G. Fluctuations of radial artery distensibility throughout the menstrual cycle. Arterioscler Thromb Vasc Biol. 1999 Aug; 19(8):1925-9.

4. Suzuki T., Matsuura T., Ohkawa K., Miyamura T., Okazaki I., Watanabe T,, Suzuki T. All-trans retinoic acid down-regulates human albumin gene expression through the induction of C/EBPbeta-LIP. Biochem J. 2006; 397 (2): 345-53.

5. Hall, Ph.D.; Cecil E.; Slayter S.H. The Fibrinogen Molecule: Its Size, Shape, and Mode of Polymerization. The Journal of Biophysical and Biochemical Cytology. Plate 1 (Cambridge, M: e Department of Biology, Massachusetts Institute of Technology). 1958 Volume 5 (1): 11-6.

6. Farrugia A. Albumin usage in clinical medicine: tradition or therapeutic?. Transfus Med Rev 2010; 24 (1): 53-63.

7. Marucco, Arianna; et al. Interaction of fibrinogen and albumin with titanium dioxide nanoparticles of different crystalline phases. Journal of Physics. 2013; Conference Series 429 (Issue 1).

8. Acharya S.S., Dimichele D.M. Rare inherited disorders of fibrinogen". Haemophilia : the Official Journal of the World Federation of Hemophilia 2008; 14 (6): 1151-8.

9. Lang T., Johanning K., Metzler H., Piepenbrock S., Solomon C., Rahe-Meyer N., Tanaka K.A. The effects of fibrinogen levels on thromboelastometric variables in the presence of thrombocytopenia. Anesthesia and Analgesia 2009; 108 (3): 751-8.

10. Koriem K.M., Soliman R.E. Chlorogenic and caftaric acids in liver toxicity and oxidative stress induced by methamphetamine. J Toxicol. 2014; 2014:583494.

11. Rondi S., Peddolla R., Venisetty R.K. Neuro, cardio, and reno protective activities of rosuvastatin in streptozotocin-induced type 2 diabetic rats undergoing treatment with metformin and glimepiride. J Adv Pharm Technol Res. 2014 Apr; 5(2):78-83.

12. Mustafa H.N., El Awdan S.A., Hegazy G.A. Protective role of antioxidants on thioacetamide induced acute hepatic encephalopathy: biochemical and ultrastructural study. Tissue Cell. 2013 Oct; 45(5):350-62.

13. Eigbibhalu U.G., Albert Taiwo E.O., Douglass I.A., Abimbola E.A. Effect of selected anti-malarial drugs on the blood chemistry and

\section{Competing interests statement}

None of the authors has any competing interests in the manuscript.

Acknowledgment: This study was funded by Scholarship by the Experimental Research Centre ELPEN Pharmaceuticals (E.R.C.E), Athens, Greece. The research facilities for this project were provided by the aforementioned institution. brain serotonin levels in male rabbits. Pak J Pharm Sci. 2013 Jan; 26(1):125-9.

14. Daimon M., Konta T., Oizumi T., Karasawa S., Kaino W., Takase K., Jimbu Y., Wada K., Kameda W., Susa S., Saito T., Kubota I., Kayama T., Kato T. Higher plasma renin activity is a risk factor for total mortality in older Japanese individuals: the Takahata study. Metabolism. 2012 Apr; 61(4):504-11.

15. Zhang H., Shu Y., Zhang J., Tong E. Dynamics of nutritional status in dying patients with acute cerebral infarction in central China: a preliminary study. Neurol Res. 2011 Jun; 33(5):503-7.

16. Okokon J.E., Nwafor P.A., Ekpo M.D. Subchronic toxicity studies of the ethanolic root extract of Croton zambesicus. Pak J Pharm Sci. 2010 Apr; 23(2):160-9.

17. Obochi G.O., Amali O.O., Ochalefu D.O. Effect of melatonin and caffeine interaction on caffeine induced oxidative stress and sleep disorders. Niger J Physiol Sci. 2010 Nov 24; 25(1):17-24.

18. Asano K., Nakano T., Takeda T., Ohkuma H. Risk factors for postoperative systemic complications in elderly patients with brain tumors. Clinical article. J Neurosurg. 2009 Aug; 111(2):258-64.

19. Sukumaran K., Pal A.K., Sahu N.P., Dalvi R.S., Debnath D. Haemato-biochemical responses and induction of HSP70 to dietary phosphorus in Catla catla (Hamilton) fingerlings. Fish Physiol Biochem. 2008 Dec; 34(4):299-306.

20. Mohebbi-Fani M., Shekarforoosh S., Maleki M., Vahedi N. Primary evaluation of methenamine as a NPN compound with probable effects on increasing ruminal escaped protein. J Vet Med A Physiol Pathol Clin Med. 2002 Jun; 49(5):239-43.

21. Foley J.E., Lapointe J.M., Koblik P., Poland A., Pedersen N.C. Diagnostic features of clinical neurologic feline infectious peritonitis. J Vet Intern Med. 1998 Nov-Dec; 12(6):415-23.

22. Mohamed O.S., Ahmed K.E., Adam S.E., Idris O.F. Toxicity of cotoran (fluometuron) in Desert sheep. Vet Hum Toxicol. 1995 Jun; 37(3):214-6.

23. Stewart D.J., Grewaal D., Green R.M., Mikhael N., Goel R., Montpetit V.A., Redmond M.D. Concentrations of doxorubicin and its metabolites in human autopsy heart and other tissues. Anticancer Res. 1993 Nov-Dec; 13(6A):1945-52.

24. Takagi K., Umezawa T., Saji T., Morooka K., Matsuo N. Meningoencephalitis in Kawasaki disease. No To Hattatsu. 1990 Sep; 22(5):429-35.

25. Hoffman A., Levy G. Kinetics of drug action in disease states. XXXVI: Effect of cyclosporine on the pharmacodynamics and pharmacokinetics of a barbiturate (heptabarbital) in rats. J Pharm Sci. 1990 Jan; 79(1):19-22. 
26. Wanwimolruk S., Levy G. Kinetics of drug action in disease states. $X X$. Effects of acute starvation on the pharmacodynamics of phenobarbital, ethanol and pentylenetetrazol in rats and effects of refeeding and diet composition. J Pharmacol Exp Ther. 1987 Jul;242(1):166-72.

27. Auer L., Petek W. Serum globulin changes in patients with craniocerebral trauma. J Neurol Neurosurg Psychiatry. 1976 Nov; 39(11):1076-80.

28. T.J. Fowler, J.W. Scadding. Clinical Neurology. C. E. Shaw: 13. Motor neurone disease and spinal muscular atrophies. Third edition. Oxford University Press Inc. London 2003; p 267.

29. Peng W., Robertson L., Gallinetti J., et al. Surgical stress resistance induced by single amino acid deprivation requires $\mathrm{Gcn} 2$ in mice. Sci Transl Med. 2012 Jan 25; 4(118):118ra11.

30. Nayak A.R., Kashyap R.S., Kabra D., et al. Evaluation of routinely performed hematological and biochemical parameters for the prognosis of acute ischemic stroke patients. Neurol Sci. 2011 Oct; 32(5):855-60.

31. van der Hoeven J.A., Molema G., Ter Horst G.J., et al. Relationship between duration of brain death and hemodynamic (in)stability on progressive dysfunction and increased immunologic activation of donor kidneys. Kidney Int. 2003 Nov; 64(5):1874-82.

32. Loehe F., Mueller C., Annecke T., et al. Tissue damage of non-heart-beating donor lungs after long-term preservation: evaluation of histologic alteration, bronchoalveolar lavage, and energy metabolism. Shock. 2002 Jun; 17(6):502-7.

33. Sokolowski A., Spormann H., Urbahn H., et al. Contribution of pancreatic edema and short-term ischemia to experimental acute pancreatitis in the rat. II. Behaviour of serum parameters. Z Exp Chir Transplant Kunstliche Organe. 1986; 19(6):331-9.

34. Simmons R.D., Bernard C.C., Singer G., et al. Experimental autoimmune encephalomyelitis. An anatomically-based explanation of clinical progression in rodents. J Neuroimmunol. 1982 Dec; 3(4):307-18.

35. Mrsulja B.B., Mrsulja B.J., Cvejić V., et al. Alterations of putative neurotransmitters and enzymes during ischemia in gerbil cerebral cortex. J Neural Transm Suppl. 1978;(14):23-30.

36. Shopova V.L., Dancheva V.Y., Salovsky P.T., et al. Protective effect of U-74389G on paraquat induced pneumotoxicity in rats. Environ Toxicol Pharmacol. 2007 Sep;24(2):167-73.

37. Moore R.M., Muir W.W., Bertone A.L., et al. Effects of dimethyl sulfoxide, allopurinol, 21-aminosteroid U-74389G, and manganese chloride on low-flow ischemia and reperfusion of the large colon in horses. Am J Vet Res. 1995 May; 56(5):671-87.

38. Vignes J.R., Hugon J. In vitro efficacy of three lazaroids in a model of acute chemical neuronal hypoxia. Neurosci Lett. 2006 Oct 23; 407(2):171-5

39. Acka G., Sen A., Canakci Z., Yildiz S., Akin A., Uzun G., Cermik H., Yildirim I., Kokpinar S. Effect of combined therapy with hyperbaric oxygen and antioxidant on infarct volume after permanent focal cerebral ischemia. Physiol Res. 2007; 56(3):369-73.

40. Horáková L., Ondrejicková O., Bachratá K., Vajdová M. Preventive effect of several antioxidants after oxidative stress on rat brain homogenates. Gen Physiol Biophys. 2000 Jun;19(2):195-205.

41. Corasaniti M.T., Strongoli M.C., Piccirilli S., Nisticò R., Costa A., Bilotta A., Turano P., Finazzi-Agrò A., Bagetta G. Apoptosis induced by gp120 in the neocortex of rat involves enhanced expression of cyclooxygenase type 2 and is prevented by NMDA receptor antagonists and by the 21-aminosteroid U-74389G Biochem Biophys Res Commun. 2000 Aug 11;274(3):664-9.

42. VIkolinský R., Stolc S. Effects of stobadine, melatonin, and other antioxidants on hypoxia/reoxygenation-induced synaptic transmission failure in rat hippocampal slices. Brain Res. 1999 Dec 11; 850(1-2):118-26.

43. Durmaz R., Deliorman S., Isiksoy S., Uyar R., Erol K., Tel E. Antiproliferative properties of the lazaroids U-83836E and U-74389G on glioma cells in vitro. Pathol Oncol Res. 1999;5(3):223-8.

44. Kondziolka D., Mori Y., Martinez A.J., McLaughlin M.R., Flickinger J.C., Lunsford L.D. Beneficial effects of the radioprotec- tant 21-aminosteroid U-74389G in a radiosurgery rat malignant glioma model. Int J Radiat Oncol Biol Phys. 1999 Apr 1;44(1):179-84.

45. Schmid-Elsaesser R., Hungerhuber E., Zausinger S., Baethmann A., Reulen H.J. Neuroprotective efficacy of combination therapy with two different antioxidants in rats subjected to transient focal ischemia Brain Res. 1999 Jan 23; 816(2):471-9.

46. Kondziolka D., Somaza S., Martinez A.J., Jacobsohn J., Maitz A., Lunsford L.D., Flickinger J.C. Radioprotective effects of the 21-aminosteroid U-74389G for stereotactic radiosurgery. Neurosurgery. 1997 Jul; 41(1):203-8.

47. Marion D.W., White M.J. Treatment of experimental brain injury with moderate hypothermia and 21-aminosteroids. J Neurotrauma. 1996 Mar; 13(3):139-47.

48. Stanimirovic D.B., Wong J., Ball R., Durkin J.P. Free radical-induced endothelial membrane dysfunction at the site of blood-brain barrier: relationship between lipid peroxidation, Na,K-ATPase activity, and 51Cr release. Neurochem Res. 1995 Dec; 20(12):1417-27.

49. Smith D., Wallom K.L., Williams I.M., Jeyakumar M., Platt F.M. Beneficial effects of anti-inflammatory therapy in a mouse model of Niemann-Pick disease type C1. Neurobiol Dis. 2009 Nov; 36(2):242-51.

50. Tripathy D., Grammas P. Acetaminophen inhibits neuronal inflammation and protects neurons from oxidative stress. J Neuroinflammation. 2009 Mar 16;6:10.

51. Bates K.A., Martins R.N., Harvey A.R. Oxidative stress in a rat model of chronic gliosis. Neurobiol Aging. 2007 Jul; 28(7):995-1008.

52. Bimpis A., Papalois A., Tsakiris S., Kalafatakis K., Zarros A., Gkanti V., Skandali N., Al-Humadi H., Kouzelis C., Liapi C. Modulation of crucial adenosinetriphosphatase activities due to $\mathrm{U}-74389 \mathrm{G}$ administration in a porcine model of intracerebral hemorrhage. Metab Brain Dis. 2013 Sep; 28(3):439-46.

53. Bimpis A., Papalois A., Tsakiris S., Zarros A., Kalafatakis K., Botis J., Stolakis V., Zissis K.M., Liapi C. Activation of acetylcholinesterase after U-74389G administration in a porcine model of intracerebral hemorrhage. Metab Brain Dis. 2012 Jun; 27(2):221-5.

54. Durmaz R., Ertilav K., Akyüz F., Kanbak G., Bildirici K., Tel E. Lazaroid U-74389G attenuates edema in rat brain subjected to post-ischemic reperfusion injury. J Neurol Sci. 2003 Nov 15; 215(1-2):87-93.

55. Clement H.W., Grote C., Heiser P., Wesemann W. Effect of lazaroid pretreatment on dopamine-induced impairment of the rat nigrostriatal system. J Neural Transm. 2002 May; 109(5-6):673-82.

56. Zhang F., Zhou L., Huang F., Liang Y., Zhang G. U-74389G suppresses lipid peroxidation and apoptosis following focal cerebral ischemia and reperfusion in rats. Chin Med J (Engl). 1998 Sep; 111(9):838-41.

57. Kim G.W., Sugawara T., Chan P.H. Involvement of oxidative stress and caspase-3 in cortical infarction after photothrombotic ischemia in mice. J Cereb Blood Flow Metab. 2000 Dec; 20(12):1690-701.

58. Heim C., Kolasiewicz W., Sontag K.H. The effects of the 21-aminosteroid U-74389G on spatial orientation in rats after a cerebral oligemic episode and iron-induced oxidative stress. Neural Transm. 2000; 107(1):95-104.

59. Hülsmann S., Kohling R., Greiner C., Moskopp D., Lücke A., Wassmann H., Speckmann E.J. Neuroprotection by 21-aminosteroids: insights from latencies of anoxic terminal negativity in hippocampus slices of guinea pig. Neurol Res. 1999 Apr; 21(3):305-8.

60. Fabian R.H., Dewitt D.S., Kent T.A. The 21 -aminosteroid U-74389G reduces cerebral superoxide anion concentration following fluid percussion injury of the brain. J Neurotrauma. 1998 Jun; 15(6):433-40.

61. Bagetta G., Palma E., Piccirilli S., Nisticò G., Dolly J.O. Seizures and hippocampal damage produced by dendrotoxin- $\mathrm{K}$ in rats is prevented by the 21-aminosteroid U-74389G. Exp Neurol. 1997 Sep; 147(1):204-10.

62. Lee S.H., Kondoh T., Camarata P.J., Heros R.C. Therapeutic time window for the 21-aminosteroid, U-74389G, in global cerebral ischemia. Neurosurgery. 1996 Mar; 38(3):517-21. 
63. Zhang J., Piantadosi C.A. Prolonged production of hydroxyl radical in rat hippocampus after brain ischemia-reperfusion is decreased by 21-aminosteroids. Neurosci Lett. 1994 Aug 15;177(1-2):127-30.

64. Farbiszewski R., Chwiecko M., Ustymowicz J. The 21-aminosteroid U-74389G protects the antioxidant enzymes in the ischemia/ reperfusion-induced rat brain damage. Eur J Pharmacol. 1994 Apr 4; 270(2-3):263-5.

65. Van Dyke K. The possible role of peroxynitrite in Alzheimer's disease: a simple hypothesis that could be tested more thoroughly. Med Hypotheses. 1997 May; 48(5):375-80.

66. C. Tsompos, C. Panoulis, K. Toutouzas, G. Zografos, A. Papalois. The effect of the antioxidant drug "U-74389G" on alkaline phosphatase levels during ischemia reperfusion injury in rats. J. Exp. Clin. Med., 2014; 31:99-102.
67. C. Tsompos, C. Panoulis, K. Toutouzas, G. Zografos, A. Papalois. The effect of the antioxidant drug "U-74389G" on sodium levels during ischemia reperfusion injury in rats. Crit Care \& Shock 2014; 2:31-36.

68. C. Tsompos, C. Panoulis, K. Toutouzas, G. Zografos and A. Papalois. The effect of the antioxidant drug "U-74389G" on chloride during ischemia reperfusion injury in rats. Medical review 2014; 50(2):40-44.

69. C. Tsompos, C. Panoulis, K. Toutouzas, G. Zografos, A. Papalois. The effect of the antioxidant drug "U-74389G" on phosphorus levels during ischemia reperfusion injury in rats. Psychogeriatria Polska 2013; 10(3): 103-108 